\title{
Quality Control: A Cornerstone to Quality - Measurement and Motivation are Key Issues
}

\author{
Rikard Almgren \\ (Invited speaker) \\ RSA Software Quality Systems \\ Östergökssvängen 61 \\ S-163 54 Spånga, Sweden
}

\begin{abstract}
The primary objective of quality control is to determine the extent to which a product exhibits required software qualities. Quality control may apply to static quality attributes, i.e., attributes of design, code and documents that one can measure without executing the product, as well as to dynamic quality attributes, which may be considerably more difficult to measure.

Objective and well defined quality requirements have to be developed and specified to serve as the yardstick by which quality controllers can measure quality. Quality requirements negotiated and agreed with the client constitute a well-defined contract regarding the criteria of high quality.

Quality control also measures the process quality to detect roadblocks in the development environment that interfere with achieving software product quality. High process quality is a prerequisite for producing high product quality. Appropriate set of development and configuration tools, continuous coaching of project members, clear project organisation and senior management commitment ensure high process quality and job satisfaction. Motivated personnel enforce success.
\end{abstract}

Rikard Almgren studied mathematics, computer science and economics at the University of Stockholm (B.Sc. 1974). He has five years of experience in developing real-time systems for air traffic control and defence systems, primarily in the areas of system software and methods \& techniques. Experiences from the financial industries were gained over eight years at Philips where he specialised in methods \& techniques, tools, and software quality engineering. He is a member of IEEE, ACM and the Swedish Quality Association (SFK). 